Résumés des conférences et travaux

\title{
Érudition historique et philologique de l'Âge classique aux Lumières
}

Jean-Louis Quantin

\section{OpenEdition}

\section{Journals}

Édition électronique

URL : https://journals.openedition.org/ashp/1348

DOI : $10.4000 /$ ashp.1348

ISSN : 1969-6310

Éditeur

Publications de l'École Pratique des Hautes Études

\section{Édition imprimée}

Date de publication : 1 octobre 2012

Pagination : 258-262

ISSN : 0766-0677

\section{Référence électronique}

Jean-Louis Quantin, «Érudition historique et philologique de l'Âge classique aux Lumières », Annuaire de l'École pratique des hautes études (EPHE), Section des sciences historiques et philologiques [En ligne], 143 | 2012, mis en ligne le 26 septembre 2012, consulté le 03 août 2021. URL : http:// journals.openedition.org/ashp/1348; DOI : https://doi.org/10.4000/ashp.1348 


\title{
ÉRUDITION HISTORIQUE ET PHILOLOGIQUE DE L'ÂGE CLASSIQUE AUX LUMIÈRES
}

\author{
Directeur d'études : M. Jean-Louis QuANTIN
}

Programme de l'année 2010-2011 : I. Culture gallicane et orthodoxie romaine : Giovanni Bona censeur d'après les archives du Saint-Office et de l'Index. - II. Politique, religion et érudition en Angleterre: John Selden et l'Antiquité chrétienne.

I. La première partie de l'année a été passée à reprendre la question des rapports entre Giovanni Bona (1609-1674, cardinal en 1669) et la culture gallicane, sur la base des documents désormais accessibles aux Archives de la congrégation pour la Doctrine de la Foi (fonds de l'Index et du Saint-Office). Il est connu depuis longtemps, aussi bien, que Bona entretint des rapports privilégiés avec le monde gallican. Les sources utilisées jusqu'ici, - sa correspondance avec les bénédictins de Saint-Maur et d'autres érudits français, les remerciements qui lui sont adressés dans leurs ouvrages, les nombreuses mentions qui sont faites de lui dans les lettres de dom Antoine Durban, procureur général de la Congrégation de Saint-Maur à Rome, - paraissent attester des dispositions très favorables aux courants augustiniens et rigoristes d'au-delà des monts, au point que Bona, au XVII ${ }^{\mathrm{e}}$ siècle même, puis de nouveau dans une controverse éclairante des années 1950, fut accusé de jansénisme ${ }^{1}$. Or les vota rédigés par Bona en sa capacité de censeur pour les congrégations romaines de l'Index (où il fut nommé consulteur en 1655) et du Saint-Office (il en devint qualificateur en 1663 et fut promu consulteur en 1667) donnent une impression tout à fait différente.

On a donc étudié un par un les principaux vota rédigés par Bona sur des ouvrages français, en les rapportant aux ouvrages eux-mêmes et en les comparant, lorsqu'ils existent, aux rapports parallèles faits par d'autre censeurs :

- Jean de Launoy, Censura responsionis qua Fr. Norbertus Caillocius sese mendaciis atque erroribus nouis irretiuit, Paris, 1663, examiné par Bona pour l'Index en 1664 ;

- Ordonnance de Monseigneur l'Illustrissime et Reverendissime Hardoüin de Perefixe, Archevesque de Paris. Touchant les Festes qui doivent estre observées dans tout son Diocese, Paris, 1666, examinée par Bona dans le cadre d'une congrégation particulière du Saint-Office en 1667;

- Ordo diuini officii recitandi iuxta ritum Breuiarii et Missalis Romani; ad usum Dioecesis Santonensis : anno Dom. M.DC.LXIX. [...]. Iussu Illustrissimi ac

1. Guido Pettinati, «Il cardinal Giovanni Bona e il giansenismo (1609-1674)», Analecta Gregoriana, t. LXXI (1954) [Nuove ricerche storiche sul giansenismo], p. 85-137; Lucien Ceyssens, « Le cardinal Jean Bona et le jansénisme, autour d'une récente étude », Benedictina, t. X (1956), p. 79-120 et 267328, repris dans Jansenistica Minora, t. IV, Malines, 1958, no 32, paginé à part p. 1-103. 
Reverendissimi Domini D. Ludovici de Bassompierre Episcopi Santonensis editus, Saintes, 1668, examiné dans le même cadre en 1669;

- Jean-Baptiste Thiers, De festorum dierum imminutione liber, pro Defensione Constitutionum Urbani VIII. et Gallicanae Ecclesiae Pontificum, Lyon, 1668 : Bona, devenu cardinal alors que l'examen était en cours ne rédigea finalement pas de votum, mais il dressa, en juillet 1670, une liste des corrections à faire;

— Étienne Guerry, Messe paroissiale d'obligation prouvée par l'Escriture saincte, les Conciles, les Decrets des Papes, Ordonnances des Evesques, anciens Cartulaires, et Coustumes de chasque païs. Seconde Edition. Avec la Censure de Iacques de Vernant, Poitiers, P. Amassard, [1664], examiné par Bona pour l'Index en 1667 (en utilisant une édition de relance datée de 1666);

- Censura Sacrae Facultatis Theologiae Parisiensis, in Librum cui titulus est : La Deffense de l'authorité de N. S. P. le Pape, de Nosseigneurs les Cardinaux, les Archevesques et Evesques, et de l'employ des Religieux mendiants, contre les erreurs de ce temps, par Jacques de Vernant, à Mets, 1658, Paris, 1664, et Censura Sacrae Facultatis Theologiae Parisiensis, in Librum cui titulus est, Amadaei Guimenii Lomarensis olim primarii Sacrae Theologiae Professoris opusculum, singularia uniuersae fere Theologiae Moralis complectens [...], Paris, 1665 : les théologiens du Saint-Office, dont Bona, examinèrent ces deux censures de Sorbonne en mai 1665, pour préparer leur condamnation par le pape Alexandre VII (bulle Cum ad aures);

- Louis Gorin de Saint-Amour, Journal de ce qui s'est fait à Rome dans l'Affaire des Cinq Propositions, s. 1., 1662, examiné par Bona pour le Saint-Office en février 1664 ;

- [Pierre Nicole], Les Imaginaires, ou lettres sur l'Heresie Imaginaire. Par le $S^{r}$ de Damvilliers, 2 vol., Liège, 1667, examiné par Bona pour l'Index en décembre 1666 (les références de Bona, qui donnent une pagination distincte pour chaque lettre, montrent qu'il a en fait utilisé les éditions originales in- $4^{\circ}$, publiées séparément);

- François Combefis, Historia haeresis monothelitarum, sanctaeque in eam sextae Synodi Actorum, Vindiciae. Diuersorum item antiqua, ac medii aeui, tum historiae sacrae, tum Dogmatica, Graeca Opuscula, Paris, 1648, examiné par Bona pour l'Index en 1660, en réaction à l'utilisation de l'ouvrage par les jansénistes;

- Le Nouveau Testament de Nostre Seigneur Jesus Christ, Traduit en François selon l'edition Vulgate, avec les differences du Grec, Mons, 1667, soumis à un examen très approfondi au Saint-Office en 1668 : Bona rendit d'abord un rapport général puis une censura détaillée de dix-neuf passages litigieux;

- Rituel romain du Pape Paul Và l'usage du diocese d'Alet. Avec les Instructions et les Rubriques en François, Paris, 1667 : Bona en rédigea une longue censura pour le Saint-Office en 1668.

Bona condamna systématiquement les gallicans qui niaient ou relativisaient les prérogatives pontificales, même quand, dans le cas de Combefis, ils le faisaient sur le mode de l'érudition historique plutôt que sur celui de la polémique théologique. Ses censurae se recoupent très largement avec celles des autres censeurs, témoignant d'un consensus théologique romain, dont Bona, contre les gallicans, participe pleinement. Il y eut un cas où il se démarqua clairement de ses collègues, celui du Nouveau Testament de Mons, dont il prit la défense : l'érudition textuelle de Bona, sa pratique 
de la théologie positive, peut-être aussi sa connaissance des caractères propres du catholicisme français, lui donnaient ici une ouverture d'esprit que ne pouvaient avoir des théologiens purement scolastiques. Mais il s'agit d'une exception dans l'activité censoriale de Bona. Même quand les prérogatives pontificales n'étaient pas directement en cause, il blâma le retour aux sources antiques prôné par les gallicans, dont sa culture historique lui permettait précisément de saisir les dangers. Il dénonça ainsi dans le Rituel d'Alet un projet de réformer l'Église présente sur le modèle des premiers siècles. Tandis que la culture religieuse française était dominée par une conception pessimiste du temps corrupteur, la romanité de Bona reconnaissait la valeur normative de la consuetudo, de la pratique actuelle et continuée de l'Église : de là sa défiance à l'encontre d'une exaltation, à ses yeux unilatérale, de la discipline antique. Attiré par la théologie positive et par l'érudition d'au-delà des monts, il était heurté par leur orientation clairement anti-romaine comme par leurs implications destructrices pour la vie de l’Église post-tridentine.

II. John Selden suscite actuellement un renouveau d'intérêt, dont témoignent la parution de l'énorme monographie de Gerald Toomer - monument impressionnant à bien des égards mais dont la conception purement «internaliste » de l'histoire de l'érudition, comme une galerie de grands hommes qui dialogueraient les uns avec les autres à travers les siècles, est à l'opposé de celle du directeur d'études ${ }^{1}-$, et l'organisation, bizarrement simultanée, de deux colloques, à Paris et à Oxford, en juin 2010. On a choisi de s'attacher à ses travaux sur l'Antiquité chrétienne, non seulement comme au sujet sur lequel il semblait le plus aisé d'apporter du neuf - il tient très peu de place dans le livre de G. Toomer-, mais parce que cette part de l'œuvre est spécialement intéressante pour qui souhaite replacer Selden dans le contexte de son temps au lieu de l'en abstraire.

L'Antiquité chrétienne n'est guère un domaine auquel le nom de Selden soit spontanément associé. Les études patristiques furent un chantier majeur dans l'Angleterre $\mathrm{du} \mathrm{XVII}^{\mathrm{e}}$ siècle mais, à la différence de certains de ses amis, Patrick Young ou plus encore James Ussher, Selden n'y fit, du moins directement, aucune contribution. Son œuvre est cependant riche en références aux Pères de l'Église et aux anciens conciles. Outre son édition d'Eutychius, auteur tardif mais qui traitait des origines chrétiennes, et son De Diis Syris, qui utilise beaucoup les Pères dans une perspective antiquaire, pour les informations qu'ils livrent sur les cultes païens antiques, plusieurs de ses ouvrages les plus importants, - Historie of Tithes, Uxor Ebraica, De Synedriis, consacrent de longues sections à retracer l'évolution du christianisme aux premiers siècles ${ }^{2}$. Dans des domaines comme les études orientales mais aussi l'histoire de l'Angleterre médiévale, Selden, comme l'écrivit Lord Clarendon, s'engagea « hors des

1. Gerald Toomer, John Selden: a life in scholarship, 2 vol., Oxford, 2009 (Oxford-Warburg studies).

2. John Selden, De Diis Syris Syntagmata II, Londres, 1617; id., The Historie of Tithes. That is, the Practice of Payment of them. The Positive Laws made for them. The Opinions touching the Right of them. A Review of it is also annext, which both Confirmes it and directs in the Use of it, [Londres], 1618; Eutychii Egyptii, Patriarchae Orthodoxorum Alexandrini, Scriptoris, ut in Oriente admodum Vetusti ac Illustris, ita in Occidente tum paucissimis Visi tum perraro Auditi, Ecclesiae suae Origines, éd. John Selden, Londres, 1642; John Selden, Uxor Ebraica seu De Nuptiis et Diuortiis ex Iure Ciuili, id est, 
sentiers foulés par les autres hommes ». Les textes patristiques ou conciliaires cités par Selden, en revanche, avaient déjà fait l'objet de nombreuses discussions avant lui. S'il fut original, ce ne put être que par l'usage qu'il en fit. Surtout, les Pères de l'Église faisaient partie de la culture professionnelle du groupe avec lequel Selden eut le plus souvent des relations tendues : des ecclésiastiques formés à la théologie et, plus précisément, dans l'Angleterre du XVII ${ }^{\mathrm{e}}$ siècle, à la controverse. Leur supériorité dans ce champ d'études était censée fonder leur autorité culturelle et sociale, et ils entendaient bien s'en réserver le monopole. Selden ne recommandait-il pas, du reste, de «croire son pasteur, à moins d'avoir étudié la théologie aussi bien que lui, ou plus que lui »? Pour évaluer dans quelle mesure il remplit ce programme, il fallait considérer, non seulement l'étendue de ses lectures patristiques, mais aussi sa maîtrise de la philologie - critique textuelle et surtout critique d'authenticité - qui constituait alors une compétence essentielle des théologiens.

Pour mener cet examen, on a systématiquement croisé les ouvrages de Selden avec la source exceptionnelle que constitue sa bibliothèque personnelle, connue par le catalogue que ses exécuteurs testamentaires en firent dresser en 1655, alors qu'elle se trouvait encore à Whitefriars, la résidence londonienne de Selden depuis 1639 (Bodleian Library, Ms. Selden supra 111). Les informations sont souvent incomplètes, et titres et noms parfois même mutilés - le copiste écrivit vraisemblablement sous la dictée, et sans y connaître grand-chose. Aussi est-il utile de vérifier ce catalogue de Whitefriars sur celui qui fut compilé à Oxford, au début de la décennie suivante, par le bibliothécaire de la Bodléienne, Thomas Lockey, après que le gros des livres de Selden y eurent finalement été transférés (on a utilisé deux exemplaires conservés à la Bodléienne, Ms. Add. C. 40 et Ms. Broxb. 84.10, qui est une copie mise au net pour John Vaughan, un des exécuteurs testamentaires de Selden). Ces livres sont en principe toujours à la Bodléienne, affectés d'une cote «Seld. », mais on ne peut exclure qu'aient eu lieu des substitutions de cotes ou d'exemplaires : la présence de la signa-

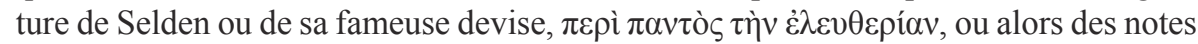
de sa main et des marques de lecture, qui correspondent souvent à des citations faites dans ses ouvrages, permettent seules d'affirmer avec certitude qu'un exemplaire lui a effectivement appartenu.

La conférence a conclu que l'information patristique de Selden n'était pas plus étendue que celle d'un docteur en théologie bien formé à Oxford ou Cambridge, et qu'il se montra, dans l'ensemble, plutôt moins critique que les controversistes savaient l'être. La représentation qu'il se faisait de l'histoire de l'Église, vue comme une usurpation progressive de la part du clergé, à partir du moment décisif de la conversion de Constantin, le rendit très vigilant vis-à-vis des textes attribués aux Pères anténicéens, mais beaucoup moins rigoureux pour les époques postérieures. Sa supériorité était d'un autre ordre. Les théologiens qui attaquèrent l'Historie of Tithes crurent que Selden faisait, au fond, la même chose qu'eux, c'est-à-dire qu'il produisait des passages patristiques à titre d'autorités. Ils ne saisirent pas que Selden avait écrit une histoire, où il avait soigneusement distingué entre opinions des Pères et constitutions de l'Église, et

Diuino et Talmudico, Veterum Ebraeorum, Libri Tres, Londres, 1646; Id., De Synedriis et Praefecturis Iuridicis ueterum Ebraeorum, 3 vol., Londres, 1650-1655. 
retracé les étapes selon lesquelles les textes patristiques (ou pseudo-patristiques) étaient devenus des canons. Les Pères pouvaient certes témoigner de ce qui se faisait de leur temps, mais il ne s'agissait que de pratiques locales, qu'on ne pouvait étendre sans plus à l'ensemble de l'Église. Une telle réflexion sur le statut des textes patristiques, qui fut certainement inspirée par la perspective juridique propre à Selden, était, à cette date, sans équivalent. L'enjeu de son travail, dès lors, était la possibilité même d'une approche non théologique de l'Antiquité chrétienne. Selden n'eut pas de vrais successeurs dans cette entreprise, du moins en Angleterre et sur le moment. Mais les théologiens retinrent une partie de ses leçons. Il dut contribuer au changement de statut des textes patristiques au XVII ${ }^{\mathrm{e}}$ siècle, de l'autorité au témoignage. Surtout, son interprétation du christianisme primitif comme « judaïsme réformé », fit de la séparation progressive entre judaïsme et christianisme une problématique centrale de l'érudition anglicane. 